\title{
Formalism of E-Commerce for SME of Pottery
}

\section{Formalismo de Comercio Electrónico para PyMES de Alfarería}

GONZÁLEZ-CASTOLO, Juan Carlos $\dagger^{*}$, RAMOS-CABRAL, Silvia and ZATARAIN-DURÁN, Omar Alí

Universidad de Guadalajara

ID $1^{\text {st }}$ Author: Juan Carlos, González-Castolo / ORC ID: 0000-0003-2659-0646, Researcher ID Thomson: R-5580-2018

ID $1^{\text {st }}$ Coauthor: Silvia, Ramos-Cabral / ORC ID: 0000-0003-4204-1700, Researcher ID Thomson: R-7124-2018

ID $2^{\text {nd }}$ Coauthor: Omar Alí, Zatarain-Durán / ORC ID: 0000-0002-7934-7765, Researcher ID Thomson: E-2222-2019

DOI: $10.35429 / J E S .2019 .5 .3 .1 .8$

Received July 11, 2019; Accepted December 03, 2019

\begin{abstract}
This work presents the essential elements that must be contained in marketing strategy oriented to virtual commerce, which is colloquially known as e-commerce. The presentation of the mentioned elements is done from a reflexing of some concepts that are formally showed. It is to say that the dissertation on the validity of the proposal is supported by mathematical approaches. Although the exhibition of this research is acceptable for all types of Small and Medium Enterprises (SME), it is focused on the characteristics and needs of the pottery industry. The elements of the proposed marketing strategy are aimed at maximizing the customers shopping experience. The essential questions addressed are 1) How to keep customers to contact with products? 2) How to make customers feel that they are served? 3) How to get buyers to remain as customers and attract more? 4) How can buyers help to improve e-commerce? 5) What is the trend of the marketing strategy for e-commerce?
\end{abstract}

E-commerce, ICT, SME

\section{Resumen}

Este trabajo presenta los elementos esenciales que deben estar contenidos en la estrategia de mercadotecnia orientada al comercio virtual, que se conoce coloquialmente como comercio electrónico. La presentación de los elementos mencionados se hace a partir de una reflexión de algunos conceptos que se muestran formales. Es decir que la tesis sobre la validez de la propuesta está respaldada por enfoques matemáticos. Aunque la exposición de esta investigación es válida para todos los tipos de Pequeñas y Medianas Empresas (PyMES), se centra en las características y necesidades de la industria de la cerámica. Los elementos de la estrategia de marketing propuesta tienen como objetivo maximizar la experiencia de compra del consumidor. Las preguntas esenciales que se abordan son: 1) ¿Cómo mantener a los clientes en contacto con los productos?, 2) ¿Cómo hacer que los clientes se sientan atendidos?, 3) ¿Cómo lograr que los compradores permanezcan como clientes y atraigan a más clientes? 4) ¿Cómo pueden ayudar los compradores a mejorar el comercio electrónico? 5) ¿Cuál es la tendencia de la estrategia de marketing para el comercio electrónico?

Comercio electrónico, TIC, PyMES

Citation: GONZÁLEZ-CASTOLO, Juan Carlos, RAMOS-CABRAL, Silvia and ZATARAIN-DURÁN, Omar Alí. Formalism of E-Commerce for SME of Pottery. Journal-Economic Systems. 2019. 3-5: 1-8

\footnotetext{
* Correspondence to Author (email: jcgcastolo@ hotmail.com)

$\uparrow$ Researcher contributing as first author.
} 


\section{Introduction}

A company with a small number of employees is classified as SMEs (Saavedra García \& Tapia Sánchez, 2013), (INEGI, 2009). The pottery industries of Jalisco state are SMEs. It is known that the basic aspiration of all SMEs is to expand their market area. To achieve this, the marketing strategy needs to consider the use of information and communication technologies (ICT). Currently, the use ICT is massive (Calvo Marín \& Ospina Ospina, 2014). With the use of ICT there are vertiginous changes in the way of doing business (Barrientos Felipa, 2017) that it is known as e-bussines, and changes in social networks (González Castolo, Ramos Cabral, \& Hernández Gallardo, 2018) that introduce the social-commerce, (Lia \& Kub, 2018). The ecommerce and social-commerce are application areas of e-bussines (Grandón, Ramírez-Correa, $\&$ Luna Orrego, 2019). The discussion of socialcommerce is not included here.

There are studies that try to enhance ecommerce with various strategies such as to give compensation in automated models, (Shojaiemehr \& Rafsanjani, 2018). In the same context, there are studies such as transaction security verification ( $\mathrm{Yu}$, Ding, Liu, Wang, \& Crossley, 2018); logistics analysis and supply chain management (Yu, Wang, Zhong, \& Huang, 2017), (Pei \& Yan, 2019); study of activities to balance supply and demand (Gölgecia, Karakasb, \& Tatogluc, 2018); price prediction (Tseng, Lin, Zhou, Kurniajaya, \& Li, 2018); sales prediction (Yuan, Xu, Li, \& Lau, 2018); purchasing prediction (Dong \& Jiang, 2019); analysis of purchase intention (Dachyar \& Banjarnahor, 2017), (Ramírez-Correa, Grandón, \& Arenas-Gaitán, 2019), (Li, Feng, \& Zhai, 2019); customer loss prediction (Berger \& Kompan, 2019); analysis of elements to attract and retain customers (Choshin \& Ghaffari, 2017), (Deng \& Gao, 2018), (Jannach, Ludewig, \& Lerche, 2017), (Wu, Zhang, Tian, \& Wu, 2019), (Chen, 2019); trust analysis (Kim \& Peterson, 2017), (Sánchez-Alzate \& Montoya Restrepo, 2017), (Masseya, Wanga, \& Kyngdon, 2019); etc. This work takes the e-commerce strategy as a marketing strategy because the arguments showed are more general

This paper is organized as follow: In the next section, fundamental consideration theoretical is presented about satisfaction grade and some related concepts are also included.
Then, characteristics that the marketing strategy required is shown. Next, discussions that have implicit answers to research questions are presented. Finally, the conclusions are given.

\section{Satisfaction Grade}

The satisfaction grade ( $S G)$ of the customer (Cmer) is directly related to the grade to which the expectation $(E)$ is met regarding an object and/or service. Hereafter, the object and/or service will be called product $(P)$. The $P$ has characteristics $(\mathrm{Ch})$ to attend $E$ that are referred to as product benefit $(\mathrm{Pb})$. The $S G$ is a function of $E$ and $P b,(1)$

$$
\begin{aligned}
& S G=f(E, P b) \\
& P b=\{C h\}
\end{aligned}
$$

The $E$ is a variable that is a function of marketing $(M k)$, utilitarian constant $(K)$ and the valuation of who sells and/or where it is sold $(K p),(2)$. Then $M k$ is the variable that modifies $E$. The utilitarian constant is inherently associated with the solution of a task and/or service attention. For example, the tool is useful for doing things and pottery is useful for decorating a place.

$$
E(t)=f(M k(t), K, K p)
$$

The $S G$ is variant in time with greater importance from the acquisition of $P$ to the event of first use. The present work presents arguments from this point.

The $M k$ encourages the desire of $P$ through its $P b$ promotion. The $P$ has physical $P b$ $(P P b)$ and/or ethereal $P b(E P b)$. For example, $P P b$ refers to material type, design, texture, etc. The $E P b$ refers to comfort, status, investment, etc. Each $C h$ could be has $P P b$ or $E P b$ or both, (3).

$$
\begin{aligned}
& P P b \cup E P b \cup P P b \cap E P b \in P b \\
& \{P b\} \in C h,\{C h\} \in P \Rightarrow\{\{P b\}\} \in P \\
& \Rightarrow\{\{P P b \cup E P b \cup P P b \cap E P b\}\} \in P
\end{aligned}
$$

The $M k$ always has a presence in the market, although in some cases it is not obvious. For example, people must expose $P$ to the view of Cmer and even approach to make the offers in case of they sell pots on the public road. This practice has an implicit $M k$. 
Balance of $E$ and $P b$ is the main propose of $M k$ in order to maximize the number of greed state $(G s)$ and therefore maximize the accumulated gain (TP) in a given time. The Gs is denoted when the excitement of desire causes that the Cmer acquires $P$. The $T P$ is the sum of simple profit $(S P),(4)$. The $S P$ is the difference between the sale price $(S p)$ and the production cost $(P C)$ where $S P$ can be positive, negative or zero, (5). The variable $n_{s}(t)$ represents sold units. It should be noted that $S p$ is part of $P P b(S p \in$ $P P b)$.

$$
\begin{aligned}
& T P(t)=\sum S P(t) \\
& S P(t)=n_{S}(t) S p(t)-P C(t)
\end{aligned}
$$

The $P C$ is integrated by manufacturing cost $(M C)$, marketing cost $(M k C)$ and research $\operatorname{cost}(R C)$. The above concepts are represented as variables in function of time, (6).

$S P(t)=n_{S}(t) S p(t)-n_{p}(t) M C(t)-M k C(t)-R C(t)$

The variable $n_{p}(t)$ represents made units such that $\sum_{0}^{t} n_{s}(t) \leq \sum_{0}^{t} n_{p}(t)$. The sum of sold products tends to be equal to sum of produced products when the company has production on demand policy.

Let it assumes that all variables of equation 6 in $\mathrm{t}_{0}$ are zero. After of $\mathrm{t}_{0}, R C(t)$ value starts increment because $P$ project requires the research of the market, $P$ characteristic, material supplies, $P$ design, etc. The $R C(t)$ tends to zero after an increase, according to solve advance of $P$ proposal.

The $M k$ campaign begins shortly before this proposal is resolved. The $M k C(t)$ overlaps in time with the $M C(t)$. At first, $M C(t)$ has a higher value attributable to inexperience in $P$ elaboration, but this will tend to decrease and stabilize. The $t_{a}$ is the moment in which the $T P(t)$ has maximum negative, where receipts due to the number of sold products is equal to the $P C(t)$, Fig. 1(a). The $S P(0, t a), S P(t a, t c), S P(t c, t d)$ as well as $S P(t d, t)$ curves are not necessarily monotonic because variables are susceptible to the market, (6). The return of investment is at $t_{c}$ instant.

The maximum gain in the shortest time is in $t_{d}$ that it can be given by a high volume of purchase-sale transactions $\left(n_{s} \gg 1\right)$ or high profit for each $P$ sold $\left(n_{s}(t) S p(t) \gg P C(t)\right)$.
Due to market saturation or past the $P$ novelty period, $S P$ has a drop that it will tend to stabilize after $t_{d}$. The curve of $T P(t)$ is described in Fig. 1(b). If $T P(t)$ is negative after $t_{d}$ it means that $C m e r$ loses interest in $P$.

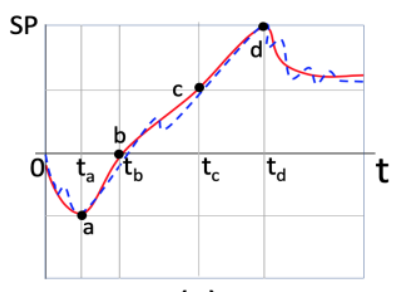

(a)

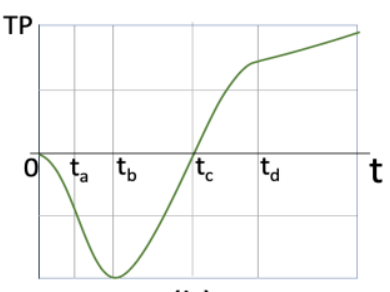

(b)
Figure 1 Illustrative curve of SP and TP

Let's define, sales success as the fact of obtaining a profit of twice the investment in half of the time that product takes to appear on the market from $P$ project start.

\section{Valuation and Opinion}

The $S G$ is displayed internally as valuation (Val) and externally through opinion $(O p)$. The $O p$ is the $\mathrm{Val}$ manifestation, and they are directly proportional with variations over time. The Val can be seen as a variable that is due to Cmer interaction with $P$ (continuous qualitative variable) and $O p$ as the manifestation of said $\mathrm{Val}$ at a given moment (discrete qualitative variable). After $P$ introduction in the market, $O p$ in the short-term pushes operations purchase-sale due $C m e r$ focused attention over this $P$. The $O p$ on the medium and long term is more related to stability and/or $P$ life in the market. The Val can be seen as the difference between $P b$ and $E$, (7). If $P b$ is greater than $E$ then it has a supra Val $\left(V^{+}\right)$and otherwise, it has an infra $\operatorname{Val}\left(V^{-}\right)$. With $V^{+}$a positive opinion $\left(O p^{+}\right)$is expressed and with $V^{-}$a negative opinion $\left(\mathrm{Op}^{-}\right)$is said, (7). An atypical case occurs when $P b$ is equal to $E$ because $C m e r$ always takes a position with his $O P$ in a positive or negative way, (8).

$$
\begin{aligned}
& V a l=\left.(P b-E)\right|_{V^{+} \Rightarrow O p^{+}} ^{V^{-}} \Rightarrow O p^{-} \\
& (P b=E) \in \emptyset
\end{aligned}
$$

The unbalance between $P b$ and $E$ is revealed through $O p$. The $O p$ is positive $\left(O p^{+}\right)$ when $P b$ satisfy $E$ otherwise it is negative $\left(O p^{-}\right)$. For all practical purposes it has that $O p^{+}=1$ and $O p^{-}=-1$. The $O p^{-}$has more influence in the market than $O p^{+}$then weight of $O p^{-}\left(w_{O p^{-}}\right)$ is greater than weight of $\mathrm{Op}^{+}\left(w_{O p^{+}}\right)$, (9). The $K_{u}$ is an adjustment constant. The product qualification $(P Q)$ is defined as the difference of $w_{O p^{+}}$sum and $w_{O p^{-}}$sum, (10).

GONZÁLEZ-CASTOLO, Juan Carlos, RAMOS-CABRAL, Silvia and ZATARAIN-DURÁN, Omar Alí. Formalism of E-Commerce for SME of Pottery. Journal-Economic Systems. 2019 
The product qualification perception $(P Q P)$ is obtained with $P Q$ that results as positive (pos) or negative (neg), (11). If $P$ is associated with a brand and/or commercial space then $P Q$ contributes to the company perception and/or place. This will be referred as company qualification perception (CQP), (12).

$$
\begin{aligned}
& \begin{array}{c}
w_{O p^{+}} \equiv O p^{+} \\
w_{O p^{-}}=K_{u} w_{O p^{+}}
\end{array} \mid K_{u} \in \mathbb{N} \\
& P Q=\sum w_{O p^{+}}-\sum w_{O p^{-}} \mid P Q \in \mathbb{Z} \\
& P Q<0 \Rightarrow P Q P=\text { neg } \\
& P Q>0 \Rightarrow P Q P=\text { pos } \\
& C Q P=\sum_{P} P Q_{P}
\end{aligned}
$$

Since $M k$ adjusts $E$ with $P b$ then optimization of the marketing cost index $(M c)$ is obtained with more balance between them. The $M c$ is a function of $P Q$ and $\mathrm{n}_{\mathrm{s}},(13)$. The $O P$ quantity is not necessarily equal to $\mathrm{n}_{\mathrm{s}}$. The $M c$ describes the acceptance of $P$ in the market whose sign is equals to $P Q$.

$$
M c=\frac{P Q}{n_{s}} \mid n_{s} \in \mathbb{N} ; M c \in \mathbb{R}
$$

If $M c \cong 1$ means that $P Q$ is equal or approximate to $\mathrm{n}_{\mathrm{s}}$ and it is a maturity position of $M k$ since $P b$ is balanced with $E$. If $M c$ moves away from 1 in the negative sense $(M c \prec 1)$ then $E$ is higher than $P b$.

This means that $M k$ must be corrected because the consumer is not properly informed and this has felt as cheating. Correct $M k$ does not mean increase $M k C$. Finally, if $M c$ moves away from 1 in a positive direction $(M c>1)$ then $P b$ is higher than $E$. The above reveals that there is a potential market to offer $P$. The strategy of $M k$ can be extended to publicize $P$ and promote $G s$ in order to increase $S P$ through increasing $\mathrm{n}_{\mathrm{s}}$. As in the previous case, extend the strategy of $M k$ it does not mean increase $M k C$.

\section{Strategy of Mk approach}

The strategy of $M k$ must ensure that $P b$ satisfies $E$ and achieve $G s$ at the same time. The introduction of $P$ in the market can be from the next strategies of $M k$ approach and/or a combination of them.

\footnotetext{
- $\quad$ Nice feeling,

- $\quad$ Service promise and/or

- Social status promise.
}

The $S p$ is part of $P P b$ in any strategy of $M k$ approach, and they are inversely proportional. This is that a $S p$ high decrement $P P b$ and vice-versa. A nice feeling can be an evocation of affection, pleasure, adventure, etc. The service promise can be the type of material, ergonomics, etc. The social status promise tries to put $C m e r$ within a privileged group. The $P$ elaboration must be careful to justify a high $S p$ in this case. A high $S p$ of the $P$ guarantees that only a select group of people has it. Moreover, the slope of $P b$ is small because $S p \ll$ $P b E \mid S p \in P b P$ and therefore $\mathrm{Val}$ is affected little. Only in the service promise, $S p$ is adjusted carefully because $P b$ is reduced with any change to rise of $S p$.

\section{Purchase-sale Transactions Valuation}

The Val can be seen in three moments associated with the purchase-sale transactions, 1) Val before, 2) Val during and 3) Val after.

The Val before is motivated with $P Q P$ and/or $M k$. The $P Q P$ is due to $O p$ of $C m e r$ that acquired $\mathrm{P}$ previously. The $M k$ affects $\mathrm{Val}$ because it promotes desire until $G s$ is obtained. The Val during is present at first approach of $C m e r$ with $P$ and it is related to $P b$ and $E$, (7). The Val after is due to $P$ integration into Cmer environment that is denoted as product use (Puse). The Val during and Val after propitiate $O p$. The $O p$ and $M k$ affect $P Q P$ and therefore Val before of new Cmer, (14).

$$
\begin{gathered}
\text { Val_before }=f(P Q P, M k) \\
\text { Val_during }=f(P b, E) \\
\text { Val_after }=f(P, \text { Val_during,Puse }) \\
\Rightarrow O p \Rightarrow P Q \Rightarrow P Q P
\end{gathered}
$$

If $P Q P$ is negative then it is illogical that Cmer buy $P$ and a reflection is not considered in this case, Table 1.

\begin{tabular}{|l|l|l|l|}
$\begin{array}{l}\text { Val } \\
\text { before }\end{array}$ & \multicolumn{1}{c|}{$\begin{array}{l}\text { Val } \\
\text { during }\end{array}$} & \multicolumn{1}{c|}{$\begin{array}{l}\text { Val } \\
\text { after }\end{array}$} & \multicolumn{1}{c|}{ Efect } \\
\hline Pos & Neg & Neg & $\begin{array}{l}\text { New P in the market with a high initial } \\
\text { sales push due to Mk whe Val during } \\
\text { and Val after does not influence Val } \\
\text { before,Val_before }=f(M k) \text { The P } \\
\text { does not penetrate the market. }\end{array}$ \\
\hline Pos & Neg & Pos & $\begin{array}{l}\text { The } M k \text { causes that } E>P b \text { and it gets Gs. } \\
\text { Although Val during is a factor that } \\
\text { influences Val after the condition gets } \\
\text { Pb E after some time. This is } \\
\text { interpreted as an erroneous strategy of Mk. }\end{array}$ \\
\hline Pos & Pos & Neg & $\begin{array}{l}\text { The P will sell well at the beginning but } \\
\text { after it will sales decrease because the } \\
\text { competition is better. }\end{array}$ \\
\hline Pos & Pos & Pos & $\begin{array}{l}\text { The P that penetrates the market with a } \\
\text { stable presence. }\end{array}$ \\
\hline
\end{tabular}

Table 1 Effect of Val of the $\mathrm{P}$ in marked

GONZÁLEZ-CASTOLO, Juan Carlos, RAMOS-CABRAL, Silvia and ZATARAIN-DURÁN, Omar Alí. Formalism of E-Commerce for SME of Pottery. Journal-Economic Systems. 2019 
According to (10), $O p^{-}$number must be lower than $O p^{+}$number or zero. The $w_{O p^{+}}<$ $w_{O p^{-}}$because $O p^{-}$is out of normality.

As has been argued before, the $M k$ has two clear objectives, 1) to look the balance between $E$ and $P b$, and 2) to induce Cmer to buy $P$. The first objective is obtained by an adequate $P$ description. The second objective is procured by stimulating Cmer senses. This last objective tries to find a pleasant and/or satisfactory image that is empathetic whit Cmer.

\section{Discussion of Strategy of $M k$}

The question of interest is, how to stimulate the desire of the Cmer? People have needs and their desire is stimulated by $P$ promoting. Then, $P$ tries to satisfy a group of specific needs whit high percent. The first contact of $C m e r$ with $P$ is fundamental because, from that, Cmer will try to recreate his positive experience or avoid his negative experience.

The strategy of $M k$ must guide Cmer also about the environment of $P$ and/or use of $P$. The environment of $P$ corresponds to the place where $C h$ of $P$ are relevant such as workshop, office, house, etc. The use of $P$ has to do with $P$ handling as ignition, maintenance, storage, etc. The strategy of $M k$ must also attend the $P$ support and $P$ life can be seen as part of $E P b$. The $P$ support has to do with the attention that company is offered post-sale. The $P$ life refers to time sure that $P$ will be in the market. The $P$ must Cmer attention attract as an element that wants to integrate into his environment and/or experience. The senses are the channel through the desire of Cmer is stimulated. Currently, the desire in e-commerce is stimulated through sense of sight and exceptionally sense of ear.

The number of senses to stimulate is reduced in e-commerce, so more attention must be paid to the strategy of $M k$. In successive will be discussed points that are within e-commerce context.

a) Consumption is the scheme of interpersonal relationships. The Cmer satisfies accompaniment wish, mitigates loneliness, and/or reduce fears through purchase-sale transactions. According to this, the communication and propagation of $P$ experience and/or $C h$ of $P$ must be facilitated.
The forums are sites that support the idea of communication and discussion.

b) Since consumption is usually emotional and not rational, then Cmer must perceive in a sideboard an empathy with his desired world. The $P$ must help to recreate and/or to modify a space where Cmer moves away from mundane everyday life.

An images catalog must try to identify a pleasant scenario where $P$ is used and/or places where it is.

c) The contribution of Cmer to images catalog helps to indicate $\mathrm{Pb}$. In addition, it exhibits the message that good choice of $P$ is distinguished.

The Cmer must have the facility to public $P$ images. The publication of images where Cmer use $P$ helps to meet $C m e r$ recognition. The validation of material before its publication attend image catalog.

d) The idiomatic messages associated with $\mathrm{P}$ contribute to $M k$ purpose because they accentuate the good Cmer decision with an acquisition. The paragraphs project knowledge and authority on $P$.

The strategy of $M k$ must have a slogan and good advice for life. In addition, it must give description, originality, temporality, and recommendations of $P$.

e) It is important to give a personalized shopping experience. The effort to attend Cmer needs should be shown.

The strategy of $M k$ must be assisted by algorithms that according to the Cmer search history and/or purchases make suggestions of new $P$. The artificial intelligence could assist here.

f) The innovation of strategy of $M k$ must be constant to find Cmer satisfaction in purchase immersion. It is desirable to stay in the mind of Cmer.

The analyst of the strategy of $M k$ is necessary to appreciate the market trend and anticipate changes. 
g)

The shopping experience should try to recreate the feeling of the ride that the Cmer would do in a physical process.

The strategy of $M k$ can be included the virtual reality of displacement through shop windows where $P$ image is amplified when the mouse cursor passes over it. With clicking on virtual $P$ is shown a box with specific information about $P$ and opinions and/or photographs. Recommendation and opinion are very important to stimulate desire.

h) The strategy of $M k$ proposition must be the idea of easy to buy, fast delivery, availability, and assistance after sales.

The strategy of $M k$ must avoid physical move inconveniences of Cmer. Also guarantee existence, diversity of payment forms, search tools, serious transaction (Sánchez-Alzate \& Montoya Restrepo, 2017), and assistance.

i) In order to have differentiators from the competition, strategies must be devised that make it difficult for competitors to enter the market.

The strategy of $M k$ should be based on the offer of some exclusive $P$.

j) Even if the strategy of $M k$ has a specific marketing portal, it should not underestimate the use social networks portals.

The $P$ offer should be made in different digital showcases such as YouTube, Reddit, Instagram, Pinterest, Facebook, Twitter, etc.

\section{Conclusions}

In synthesis, the proposed is give the Cmer what it is looking for and offer proposals that meet their needs. Pleasure to buy, feel loved, feel appreciated, feel part of an exclusive world. It convenient gives the promise to transform her environment through $P$.

The e-commerce must get the trust of $\mathrm{Cmer}$. This could be obtained with clear rules, something contributed to the community, tips given without expecting something in return, authority demonstrated, business transparency show, questions attention, and commitments fulfill.
This paper presented a formal description elementary aspect of e-commerce. The reflection shows that $S G$ is a function of $E$ and $P B$; that $M k$ modulates $E$; that $P$ has $P b$; that $S p$ is a $P b$; that $V a l$ and $O p$ are effects of $S G$; that stimulating desire gets Gs. The implicit questions had been answered in the discussion of the strategy of $M k$ section.

E-Commerce must evolve with TIC advance with the aim of offering the best shopping experience. The evolution trend of ecommerce is with the use of virtual reality, artificial intelligence, and it needs to get involved in the dynamics of virtual social networks. The future work is the strategy of $M k$ atomization in order to develop the $W E B$ portal for $S M E$ pottery.

\section{References}

Barrientos Felipa, P. (2017). Marketing + internet $=$ e-commerce: oportunidades $\mathrm{y}$ desafíos. Revista Finanzas y Política Económica , 9 (1), 41-56.

Berger, P., \& Kompan, M. (2019). User Modeling for Churn Prediction in E-Commerce. IEEE Intelligent Systems, ISSN 1541-1672, 4452 .

Calvo Marín, D. C., \& Ospina Ospina, D. H. (2014). Jóvenes y TIC: una mirada desde la vida cotidiana. 90 textos y sentidos (9).

Chen, Y. (2019). Research on personalized recommendation algorithm based on user preference in mobile e-commerce. SpringerVerlag GmbH Germany, part of Springer Nature , 1-14.

Choshin, M., \& Ghaffari, A. (2017). An investigation of the impact of effective factors on the success of e-commerce in small- and medium-sized companies. Computers in Human Behavior, ELSEVIER , 66, 67-74.

Dachyar, M., \& Banjarnahor, L. (2017). Factors influencing purchase intention towards consumer-to-consumer e-commerce. Intangible Capital, ISSN 1697-9818, 13 (5), 946-968.

Deng, Y., \& Gao, Q. (2018). A study on ecommerce customer segmentation management based on improved K-means algorithm. Information Systems and e-Business Management, Springer, 1-14.

GONZÁLEZ-CASTOLO, Juan Carlos, RAMOS-CABRAL, Silvia and ZATARAIN-DURÁN, Omar Alí. Formalism of E-Commerce for SME of Pottery. Journal-Economic Systems. 2019 
Dong, Y., \& Jiang, W. (2019). Brand purchase prediction based on time-evolving user behaviors in e-commerce. Concurrency Computat Pract Exper, 31, 1-15.

Gölgecia, I., Karakasb, F., \& Tatogluc, E. (2018). Understanding demand and supply paradoxes and their role in business-to- $\mathrm{T}$ business firms. Industrial Marketing Management, ELSEVIER , 76, 169-180.

González Castolo, J. C., Ramos Cabral, S., \& Hernández Gallardo, S. C. (2018). Reflections of Social Netwoks. Revista de Investigaciones Sociales, ISSN , 5 (9), 16-25.

Grandón, E. E., Ramírez-Correa, P. E., \& Luna Orrego, J. S. (2019). Modelo de Aplicaciones eBusiness en Grandes Empresas: Una Validación Empírica. Interciencia , 44 (4), 210-217.

INEGI. (2009). Micro, pequeña y gran empresa. Estratificación de los establecimientos. Ags: Instituto Nacional de Estadística y Geografía.

Jannach, D., Ludewig, M., \& Lerche, L. (2017). Session-based item recommendation in ecommerce: on short-term intents, reminders, trends and discounts. User Model User-Adap Inter, Springer, 351-392.

Kim, Y., \& Peterson, R. A. (2017). A Metaanalysis of Online Trust Relationships in Ecommerce. Journal of Interactive Marketing, ELSEVIER , 38, 44-54.

Li, J., Feng, L., \& Zhai, J. (2019). Multicriteria Evaluation of the Emotional Intelligence of Small Retail E-Commerce Network Firms. Mathematical Problems in Engineering, 1-8.

Lia, C.-Y., \& Kub, Y.-C. (2018). The power of a thumbs-up: Will e-commerce switch to social commerce? Information \& Management, ELSERVIER , 55, 340-357.

Masseya, G. R., Wanga, P. Z., \& Kyngdon, A. S. (2019). Conceptualizing and modeling interpersonal trust in exchange relationships: $\mathrm{T}$ The effects of incomplete model specification. Industrial Marketing Management, ELSEVIER, 76, 60-71.

Pei, Z., \& Yan, R. (2019). Cooperative behavior and information sharing in the e-commerce age. Industrial Marketing Management, ELSEVIER, $76,12-22$.
Ramírez-Correa, P. E., Grandón, E. E., \& Arenas-Gaitán, J. (2019). Assessing differences in customers' personal disposition to ecommerce. Industrial Management \& Data Systems, Emerald , 119 (4), 792-820.

Saavedra García, M. L., \& Tapia Sánchez, B. (2013). El uso de las Tecnologías de la Información y Comunicación TIC en las micro, pequeñas y medianas empresas (MIPyME) industriales mexicanas. Enl@ce Revista Venezolana de la Información Tecnología y Conocimiento , 10 (1), 85-104.

Sánchez-Alzate, J. A., \& Montoya Restrepo, L. A. (2017). La confianza como elemento fundamental en las compras a través de canales de comercio electrónico: caso de los consumidores en Antioquia (Colombia). Innovar. Revista de Ciencias Administrativas y Sociales. ISSN 0121-5051 , 27 (64), 11-22.

Shojaiemehr, B., \& Rafsanjani, M. K. (2018). A supplier offer modification approach based on fuzzy systems for automated negotiation in ecommerce. Inf Syst Front, Springer, 20, 143160.

Tseng, K.-K., Lin, R. F.-Y., Zhou, H., Kurniajaya, K. J., \& Li, Q. (2018). Price prediction of e-commerce products through Internet sentiment analysis. Electron Commer Res, Springer , 18, 65-88.

Wu, X.-q., Zhang, L., Tian, S.-1., \& Wu, L. (2019). Scenario based e-commerce recommendation algorithm based on customer interest in Internet of things environment. Springer Science+Business Media, LLC, part of Springer Nature, 1-17.

Yu, W., Ding, Z., Liu, L., Wang, X., \& Crossley, R. D. (2018). Petri net-based methods for analyzing structural security in e-commerce business processes. Future Generation Computer Systems, ELSEVIER https://doi.org/10.1016/j.future.2018.04.090, 110.

Yu, Y., Wang, X., Zhong, R. Y., \& Huang, G. (2017). E-commerce logistics in supply chain management Implementations and future perspective in furniture industry. Industrial Management \& Data Systems, Emerald , 117 (10), 2263-2286. 
Yuan, H., Xu, W., Li, Q., \& Lau, R. (2018). Topic sentiment mining for sales performance prediction in e-commerce. Big Data Analytics in Operations \& Supply Chain Management, Springer, 270, 553-576. 